\title{
CONSTRUÇÃO DE SABERES \\ NO MESTRADO PROFISSIONAL EM LETRAS: UMA EXPERIÊNCIA COMPARTILHADA ${ }^{1}$
}

\author{
Wagner Rodrigues Silva* \\ Waldeny Berson de Sousa** \\ Solange Freire de Castro Araújo ${ }^{* * *}$
}

\begin{abstract}
Resumo: Neste artigo, apresentamos o resultado de uma atividade de ensino e pesquisa desenvolvida com professoras da escola básica, responsáveis pelo ensino do Português como língua materna em escolas públicas brasileiras. A referida atividade foi orientada pela abordagem do letramento científico, e realizada como uma atividade curricular em um mestrado profissional para professores. Objetivou sustentar a tese de que a articulação de conteúdos das aulas de língua materna aos de outras disciplinas escolares pode auxiliar na elaboração de atividades produtivas de práticas de linguagens para o trabalho pedagógico na perspectiva dos estudos do letramento.
\end{abstract}

Palavras-chave: Letramento. Interdisciplinaridade. Material pedagógico. Geografia.

Abstract: This paper presents the result of a teaching and research activity developed with teachers from an elementary school who are responsible for the teaching of Portuguese as mother language in Brazilian public schools. This activity was guided by the scientific literacy approach and was carried out as a curricular task in a Master's degree program for educators. It aimed to support the thesis that the articulation of contents from mother language classes to those from other school subjects can contribute to the elaboration of productive activities of language practices for the pedagogical work in the perspective of the literacy studies.

Keywords: Literacy. Interdisciplinarity. Pedagogical material. Geography.

\section{Introdução}

\begin{abstract}
"A aula era de Geografia, e a professora traçava no quadro-negro nomes de países distantes. (...) Então, nasci. De repente nasci, isto é, senti necessidade de escrever."
\end{abstract}

(Carlos Drummond de Andrade)

A epígrafe deste artigo nos remete ao relato de Juquita, aluno, personagem e narrador do conto intitulado "Um escritor nasce e morre", produzido pelo escritor brasileiro Carlos Drummond de Andrade. Entusiasmado pela aula de Geografia ministrada por D. Emerenciana, personagem e professora que traçava no quadro-negro nomes de países com locais famosos, Juquita se entregou ao trabalho com a escrita. Nas palavras de Drummond, o

${ }^{1}$ Este artigo contribui paras as investigações científicas desenvolvidas no âmbito do grupo de pesquisa Práticas de Linguagens - PLES (UFT/CNPq). O primeiro autor deste artigo agradece ao Conselho Nacional de Desenvolvimento Científico e Tecnológico (CNPq) pela bolsa de produtividade em pesquisa (PQ-2) concedida, contribuindo portanto para produção da pesquisa apresentada neste artigo (Proc. 305094/2016-5).

* Doutor em Linguística Aplicada, professor da Universidade Federal do Tocantins (UFT), Campus de Palmas, e bolsista de Produtividade em Pesquisa do CNPq. Endereço eletrônico: wagnerodriguesilva@gmail.com

** Aluna do Mestrado Profissional em Letras (ProfLetras/UFT). Professora da Rede Pública Estadual de Ensino do Tocantins. Endereço eletrônico: waldeny.berson@gmail.com

*** Aluna do Mestrado Profissional em Letras (ProfLetras/UFT). Professora da Rede Pública Estadual de Ensino do Tocantins. Endereço eletrônico: solange.freire@hotmail.com 
aluno "escrevia com o rosto ardendo, e a mão veloz tropeçando sobre complicações ortográficas, mas passava adiante". (ANDRADE, 2012, p. 118).

Essa narrativa ajuda-nos a apresentar a principal tese deste artigo: defender a produtividade da articulação de conteúdos de diferentes disciplinas aos das aulas de Língua Portuguesa. Em outras palavras, o uso de textos que tematizem assuntos relevantes para outras disciplinas escolares contribui para a contextualização de conteúdos de Língua Portuguesa, torna as aulas mais produtivas na escola básica e evita o trabalho metalinguístico exaustivo, característico da tradição do ensino de língua materna (cf. NEVES, 1999; SILVA, 2011).

Este artigo foi escrito a seis mãos por duas professoras da escola básica e um docente do ensino superior, todos vinculados ao Mestrado Profissional em Letras (ProfLetras), na Universidade Federal do Tocantins (UFT). Diferentes vozes se misturam na escrita deste texto, assumindo o desafio da construção cooperativa de saberes acadêmicos e escolares. $\mathrm{Na}$ condição de alunas e formador do ProfLetras, lançamo-nos ao desafio de registrar parte de uma atividade de ensino e pesquisa realizada na disciplina Alfabetização e Letramento, ministrada no referido mestrado e organizada em três momentos.

No primeiro momento, investigamos como as alunas matriculadas na disciplina mencionada compreendiam alfabetização e letramento antes das aulas presenciais, bem como articulavam tais noções aos contextos de trabalho em que estavam inseridas enquanto professoras de Língua Portuguesa no Ensino Fundamental ou Ensino Médio, em diferentes redes públicas de ensino nos Estados do Maranhão (MA) e do Tocantins (TO) ${ }^{2}$.

No segundo momento, desenvolvemos um estudo crítico da $3^{\text {a }}$ Versão da Base Nacional Comum Curricular (BNCC), procurando compreender como as teorias da alfabetização e do letramento informavam a seleção dos conteúdos comuns elencados para as disciplinas escolares ministradas nas escolas brasileiras.

No terceiro momento, as professoras foram orientadas a elaborarem atividades de análise linguística a partir de textos tematizadores de conteúdos atrelados a outras disciplinas escolares, considerando a proposta curricular apresentada na BNCC (BRASIL, 2017), o que já se configurava na tese por nós defendida. Nesse sentido, compartilhamos, ao final deste artigo, uma proposta de atividade pedagógica de análise linguística a partir de uma charge cujo assunto tematizado aponta para a disciplina de Geografia.

Além desta Introdução, das Considerações finais e das Referências, este artigo está organizado em três principais seções: Construindo professoras pesquisadoras; Compreendendo a BNCC; e Proposta de atividade pedagógica problematizada. Essas seções retomam exatamente os momentos das atividades pedagógicas descritos previamente, responsáveis pela maior familiarização das professoras com efetivas práticas de investigação científica. Estas últimas culminaram com a produção deste artigo científico, que contribuiu para o exercício da escrita acadêmica das professoras.

\section{Construindo professoras pesquisadoras}

No primeiro momento da atividade, as professoras foram orientadas a apresentarem um texto escrito, antes do início das aulas presenciais, respondendo aos questionamentos reproduzidos no Exemplo 1. O comando para produção textual foi enviado para os e-mails das professoras e recomendado que elas não fizessem consultas a materiais bibliográficos para responder aos questionamentos, pois o objetivo preliminar da atividade era realizar um

\footnotetext{
${ }^{2}$ Neste artigo, optamos por utilizar o gênero feminino para fazer referência à turma do ProfLetras, uma vez que as professoras eram a grande maioria, assim como acontece nas escolas brasileiras: treze (13) professoras e dois (02) professores.
} 
diagnóstico dos conhecimentos compartilhados por elas antes do início das atividades disciplinares.

Exemplo 1: Enunciado da Atividade Escrita

Considerando sua formação e experiência profissional em sala de aula ou outros contextos de formação, como você compreende alfabetização e letramento? Quais são os prováveis/possíveis desdobramentos desses conceitos para sua prática profissional? Há demandas no seu local de trabalho para as quais os referidos conceitos precisem ser mobilizados?

Além de serem utilizados pelo formador para planejamento da disciplina, os textos escritos, com características dos gêneros ensaio acadêmico e relato de experiência, serviram como documentos para o exercício da investigação científica durante as aulas. As professoras se utilizaram de uma ficha proposta pelo formador como instrumento analítico dos textos por elas produzidos. Após dividir a turma em quatro grupos, o formador solicitou que cada grupo examinasse um aspecto questionado no comando da atividade: (1) concepções de alfabetização; (2) concepções de letramento; (3) desdobramentos das noções de alfabetização e de letramento para as práticas profissionais das professoras; e (4) demandas do local de trabalho para mobilização das noções de alfabetização e letramento. Ao final da disciplina, as análises foram compartilhadas por escrito e por exposição oral por todas as professoras. Neste artigo, focalizamos mais diretamente os dois primeiros aspectos investigados.

Exemplo 2: Ficha Analítica

\begin{tabular}{|c|c|c|c|}
\hline \multicolumn{2}{|c|}{ EQUIPE DE } & \multicolumn{2}{|c|}{ ANÁLISE } \\
\hline ANALISTAS: & EXCERTO & \\
\hline & & \\
\hline & & \\
\hline & & \\
\hline & & \\
\hline
\end{tabular}

Conforme reproduzido no Exemplo 2, a ficha analítica era composta por três colunas além de um espaço inicial para identificação da equipe de professoras responsável pelo exame dos documentos. As três colunas foram preenchidas respectivamente com as seguintes informações: (1) autoria do texto escrito; (2) reprodução do excerto responsável pela identificação do aspecto investigado; e (3) análise crítica da equipe a respeito do excerto identificado, a partir das teorias estudadas na disciplina.

Das quinze (15) professoras matriculadas na turma aqui focalizada do ProfLetras, doze (12) definiram o fenômeno da alfabetização em consonância com diferentes teorias de referência sobre o assunto. Nos textos apresentados, pudemos discernir que as professoras compreendiam o ato de alfabetizar, nos termos de Soares (2017, p. 16, grifo da autora), como "um conjunto de procedimentos que, fundamentados em teorias e princípios, orientem a aprendizagem inicial da leitura e da escrita". Nesta perspectiva, a "faceta linguística" da alfabetização predomina nas práticas pedagógicas responsáveis pelo ensino do sistema alfabético-ortográfico da língua portuguesa aos alunos.

Duas (02) professoras se equivocaram ao manifestar concepções similares de alfabetização e de letramento. Salientamos os equívocos compartilhados no campo de atuação profissional das professoras em relação às noções teóricas focalizadas. Eles podem resultar na assunção de procedimentos metodológicos pouco eficazes e, muitas vezes, prejudiciais em longo prazo. Sendo a fase da alfabetização extremamente importante na formação dos alunos, 
as práticas pedagógicas realizadas nessa fase refletirão em anos subsequentes, desdobrando-se ao longo da vida escolar dos alunos.

Destacamos a inovação da prática profissional de professoras alfabetizadoras que diferenciam suas aulas com atividades desencadeadoras do letramento, atreladas a estratégias de alfabetização. Nos termos de Soares (2017, p. 27, grifo da autora), temos "uma aprendizagem inicial da língua escrita [...] não apenas como aprendizagem [...] do sistema alfabético e suas convenções, mas [...] práticas sociais da língua escrita”. Nessa perspectiva, temos o cultivo mais amplo da cultura do letramento, na qual a professora atua como escriba, transcrevendo as falas dos discentes, ou como contadora de histórias. Então, alfabetização e letramento devem ocorrer simultaneamente, mas são exercícios distintos, complementares, é verdade, contudo com propósito de significativo diferencial.

$\mathrm{O}$ exame dos documentos mostrou ainda que há professoras que compreendem o letramento como uma extensão ou consequência da alfabetização, o que pode não se sustentar teoricamente quando se toma como referência a "faceta linguística" da alfabetização, responsável pelo enfoque dos aspectos formais da língua (cf. SOARES, 2017). Lembramos que, na sociedade grafocêntrica em que vivemos há cidadãos analfabetos, porém letrados, capazes de participar de interações sociais em que a escrita se faz presente. A decifração do sistema ortográfico-alfabético da língua portuguesa, bem como o registro escrito do insumo sonoro, em típicas atividades de alfabetização, não garantem as "habilidades" necessárias para transitar pelos diversos eventos de letramento característicos dos inúmeros domínios sociais. Uma concepção mais ampla de alfabetização, apontando para as "facetas interativas" e "socioculturais", conforme descritas por Soares (2017), pode contribuir mais diretamente para o fortalecimento dos letramentos necessários ao exercício da cidadania, porém tais facetas foram ignoradas nos dados investigados.

Certamente, muitas professoras das escolas básicas utilizam o termo letramento motivadas pelo modismo. Na realidade, as concepções se distanciam das teorias de referência. Algumas escolas estão repletas de projetos, deixando o corpo docente sobrecarregado, mas a reprovação e a evasão alcançam altos índices (cf. SILVEIRA, 2016). Este fato revela que a prática dissociada da teoria não surte os efeitos esperados. Desta forma, mesmo tendo excelentes ideias, as educadoras esbarram no insuficiente conhecimento teórico, e, assim, perpetuam falhas repetidas há décadas.

Quando se trata de alfabetização, o histórico das escolas públicas apresenta uma prática de responsabilizar iniciantes no magistério pela difícil tarefa de ensinar a ler e a escrever. Percebemos, nesta forma de ação, o errôneo pensamento de que esta fase do ensino é menos importante que os demais graus da formação discente. Na verdade, é um ledo engano. Reiteramos que a alfabetização representa a base dos estudos e precisa ter continuidade ao longo dos anos escolares por professoras responsáveis pelos diferentes "componentes curriculares". Faltam conhecimentos dos gestores e da equipe escolar como um todo, no tocante ao perfil mais adequado de uma alfabetizadora. Assim, continuam considerando a alfabetizadora inferior, desprezando a necessidade de investir nesta profissional e, consequentemente, no sucesso dos alunos. Desta mudança de visão também depende a elevação da qualidade da educação brasileira, e isto não ocorrerá se as próprias educadoras não se mobilizarem, exigindo das autoridades competentes a garantia da formação continuada para todas as regentes de sala de aula e, claro, para as alfabetizadoras.

De acordo com Street (2014, p. 201), esclarecemos que "o letramento, [...] já é parte de uma relação de poder, e o modo como as pessoas 'se apropriam' dele é uma contingência de práticas sociais e culturais e não só de fatores pedagógicos e cognitivos". Nesta perspectiva, ser letrado significa assumir a condição de dominação? Para alguns políticos, gestores públicos e, até mesmo, professoras, a resposta para o questionamento pode ser sim. Certamente, eles não defendem o efetivo letramento dos estudantes porque temem a 
autonomia discente. Como autoridades e detentores do poder, não admitem um processo de ensino e aprendizagem no qual os aprendizes participem da construção do saber.

Assim, como se dão as leituras desenvolvidas no ambiente escolar? Quase que de maneira generalizada, elas ocorrem sem articulação com a vida social dos educandos. $\mathrm{O}$ exercício de leitura escolarizada tem causado aversão dos alunos aos textos e livros, pelo caráter mecânico e autoritário como é posto. Isto é perfeitamente compreensível, pois "a leitura que não surge de uma necessidade para chegar a um propósito não é propriamente leitura; [...], estamos apenas exercendo atividades mecânicas que pouco têm a ver com significado e sentido". (KLEIMAN, 1997, p. 35). É preciso relacionar os conteúdos escolares e estratégias pedagógicas à cidadania para não haver o estranhamento dos discentes quanto ao que se estuda nas escolas e as práticas não escolares de interação social.

Retomando os documentos analisados, identificamos como principais demandas das escolas às quais as professoras estão inseridas o domínio da leitura e da escrita pelos alunos. Estas demandas se desdobram em dois desafios interconectados: (1) desafios para os alunos; e (2) desafios para as instituições. As demandas não podem ser dissociadas do letramento. Conforme a BNCC (BRASIL, 2017, p. 63), examinada na próxima seção deste artigo, “o objetivo norteador da Língua Portuguesa é garantir [...] o acesso aos saberes linguísticos necessários para a participação social e o exercício da cidadania".

As professoras mencionaram as dificuldades de leitura, escrita e, inclusive, de expressão oral como desafios a serem superados pelos alunos. No tocante aos desafios institucionais, foram relatadas ações escolares realizadas com o propósito de atender às demandas dos alunos. Mas sem a parceria dos gestores, mais preocupados com questões burocráticas, a professora trabalha solitária, sendo responsável pelo bom ou mau desempenho do aluno.

Há professoras que se incomodam em desenvolver práticas pedagógicas para o desenvolvimento das "habilidades" de leitura e escrita dos alunos, pois muitas atividades não surtem o efeito esperado. As profissionais apontam a formação continuada e a prática pedagógica interdisciplinar como fatores importantes para a melhoria do aprendizado. No entanto, identificamos críticas a programas de formação docente, nos quais são feitos altos investimentos financeiros aliados à dedicação dos professores, porém os resultados negativos têm causado inquietações.

Dados os fatos expostos, levantamos o seguinte questionamento: a leitura e a escrita são práticas escolares de linguagem a serem trabalhadas apenas em aulas de Língua Portuguesa? Faz-se necessário o engajamento coletivo, envolvendo as diversas disciplinas e seus respectivos professores, além de gestores, familiares e comunidade em geral. Desta união, podem surgir ações eficazes para a disseminação do gosto pela leitura, a exemplo dos círculos de livros, nos quais os membros trocam suas obras, em uma sequência de empréstimos de modo que cada um consegue ler um bom quantitativo do acervo do grupo. Com esta estratégia, provoca-se uma mudança nas conversas juvenis, inclusive, ocorrendo diálogos a respeito das literaturas lidas, favorecendo o interesse das crianças, adolescentes e jovens pelo mundo das letras, mudando até mesmo o cenário dos intervalos entre as aulas. Ao invés da correria, gritaria e brigas, pequenas rodas de leitura ou de jovens em processo de discussão sobre os livros já lidos. Parece utópico, mas é possível a conquista deste ideal de escola, necessitando da efetiva participação dos educadores em tal projeto. Os alunos, por sua vez, precisam também acreditar e participar da proposta. Infelizmente, inúmeros alunos estão habituados à estigmatização, às representações de indivíduos destinados ao fracasso.

Por fim, a título de exemplo, outra importante intervenção é o uso dos laboratórios de informática para realizar aulas de leitura de maneira mais dinâmica e atrativa aos alunos. É uma maneira de aproximação da escola ao universo dos estudantes, os quais demonstram "habilidades" e "competências" para o uso das tecnologias. Contudo, não basta conduzir as 
turmas à sala de informática, sem um planejamento da atividade pedagógica a ser realizada, pois o alunado é dotado de inteligência o suficiente para perceber se a educadora tem um objetivo a ser cumprido ou utiliza aquele espaço apenas como fuga para a desmotivação ou falta de estudo e preparação prévia dos conteúdos a serem ministrados. Reconhecendo tal prática, os discentes se dispersam e não se consegue mais a atenção dos mesmos para realização das tarefas propostas, passando a serem caracterizados como indisciplinados.

\section{Compreendendo a BNCC}

A Base Nacional Comum Curricular (BRASIL, 2017) consiste na terceira versão de um documento proposto para regulamentar os conteúdos comuns a serem trabalhados nas escolas brasileiras de Educação Infantil e de Ensino Fundamental. Essa versão foi encaminhada pelo Ministério da Educação (MEC) para aprovação pelo Conselho Nacional de Educação (CNE). A elaboração da BNCC (BRASIL, 2017) foi idealizada para acontecer de forma participativa, ainda que seja perceptível a surpresa de alguns educadores com algumas escolhas realizadas e apresentadas apenas na terceira versão disponibilizada. A título de exemplo de uma dessas escolhas, mencionamos a forma de apresentação dos conteúdos gramaticais para as aulas de Língua Portuguesa, conforme comentaremos adiante.

O documento possibilita a adequação dos conteúdos às circunstâncias peculiares a cada unidade escolar, tanto no aspecto humano, quanto material, considerando a qualidade do processo de ensino e de aprendizagem. O texto da BNCC (BRASIL, 2017, p. 11) faz referência à igualdade do ensino: "igualdade de oportunidades para ingressar, permanecer e aprender na escola, por meio do estabelecimento de um patamar de aprendizagem e desenvolvimento a que todos têm direito".

Outro aspecto relevante do documento é o compromisso com a educação integral, não entendida como educação de tempo integral que, muitas vezes, é reduzida, em estados e municípios brasileiros, a fins políticos, sem garantia efetiva do desenvolvimento dos trabalhos pedagógicos para o referido modelo idealizado de escola. Com a formação integral, objetivase trabalhar saberes diversos, de maneira que os conteúdos disciplinares tenham funcionalidades na vida dos alunos, garantindo-lhes o desenvolvimento de diversas "habilidades" e o exercício mais efetivo da cidadania.

No Exemplo 3, reproduzimos os objetivos para o estudo da Língua Portuguesa e da Geografia, apresentados na BNCC (BRASIL, 2017). Acrescentamos os sublinhados nos exemplos para destacar o conteúdo. Tais objetivos revelam de alguma maneira a preocupação da formação de indivíduos participativos no tocante às decisões necessárias à sobrevivência digna em sociedade.

Exemplo 3: Objetivos do estudo da Língua Portuguesa e da Geografia (BNCC)

\begin{tabular}{|c|}
\hline OBJETIVO PARA O ESTUDO DA LÍNGUA PORTUGUESA \\
\hline $\begin{array}{l}\text { O objetivo norteador da BNCC de Língua Portuguesa é garantir a todos os alunos o acesso aos saberes } \\
\text { linguísticos necessários para a participação social e o exercício da cidadania, pois é por meio da língua que } \\
\text { o ser humano pensa, comunica-se, tem acesso à informação, expressa e defende pontos de vista, partilha } \\
\text { ou constrói visões de mundo e produz conhecimento (BRASIL, 2017, p. 63). }\end{array}$ \\
\hline OBJETIVO PARA O ESTUDO DA GEOGRAFIA \\
\hline $\begin{array}{l}\text { [...] o estudo da Geografia no Ensino Fundamental - Anos Finais possa contribuir para o delineamento do } \\
\text { projeto de vida dos jovens alunos, de modo que eles compreendam a produção social do espaço e a } \\
\text { transformação do espaço em território usado. Anseia-se, também, que entendam o papel do Estado-nação } \\
\text { em um período histórico cuja inovação tecnológica é responsável por grandes transformações } \\
\text { socioespaciais, acentuando ainda mais a necessidade de que possam conjecturar as alternativas de uso do } \\
\text { território e as possibilidades de seus próprios projetos para o futuro (BRASIL, 2017, p. 335). }\end{array}$ \\
\hline
\end{tabular}


Para o estudo da Língua Portuguesa no Ensino Fundamental, são justapostas formas verbais (pensar; comunicar; ter; expressar; defender; partilhar; construir; produzir) que expressam a agência necessária dos alunos como cidadãos nas interações cotidianas. Em outras palavras, o trabalho pedagógico com os saberes linguísticos precisa garantir autonomia do aluno. Para o estudo da Geografia, o propósito descrito não é diferente, o trabalho pedagógico deve "contribuir para o delineamento do projeto de vida dos jovens alunos". Da mesma maneira, a agência dos alunos diante dos conteúdos disciplinares, articulados a demandas sociais, é expressa por formas verbais sequenciadas (compreender; entender; conjecturar).

Em relação ao Ensino Fundamental, a BNCC (BRASIL, 2017) está organizada em quatro áreas do conhecimento: Linguagens (Língua Portuguesa, Arte, Educação Física, Língua Inglesa); Matemática; Ciências da Natureza; e Ciências Humanas (Geografia, História). As áreas possuem "competências" específicas a serem desenvolvidas e, posteriormente, são apresentadas "competências" para as disciplinas escolares, que passam a ser denominadas de "componentes curriculares". Para garantir a funcionalidade dos conteúdos selecionados, cada "componente curricular" é organizado em "unidades temáticas", as quais são desdobradas em "objetos de conhecimento" atrelados a "habilidades". Alguns "componentes curriculares" são organizados em "eixos", que correspondem a maneiras como os "objetos de conhecimento" devem ser planejados para as aulas. Para a Língua Portuguesa, por exemplo, são apresentados cinco "eixos": "oralidade"; "leitura"; "escrita"; "conhecimentos linguísticos e gramaticais"; e "educação literária".

O penúltimo "eixo" mencionado gerou incômodo entre as professoras do ProfLetras. Preocupa-nos as interpretações que as professoras farão dos "objetos de conhecimentos" elencados no referido "eixo", uma vez que os conhecimentos linguísticos e gramaticais ainda são um grande desafio para os responsáveis pelo ensino de Língua Portuguesa. Considerando que a BNCC (BRASIL, 2017) não apresenta diretrizes metodológicas, algumas professoras poderão se apoiar nas recomendações oficiais para justificar um trabalhar metalinguístico descontextualizado, conforme as práticas pedagógicas da tradição do ensino gramatical (cf. NEVES, 1999; SILVA, 2011). Outras profissionais continuarão se esforçando para desenvolver atividades de análise linguística, conforme recomendado nos Parâmetros Curriculares Nacionais (BRASIL, 1998), os quais continuam em vigência dadas as funções diferenciadas entre os documentos oficiais focalizados.

Esse desafio justifica nossa proposta de apresentação de uma atividade de conhecimentos linguísticos e gramaticais ao final deste artigo. Salientamos que o texto é proposto como "o centro das práticas de linguagens" na BNCC (BRASIL, 2017, p. 63), o que nos faz lembrar a assunção do texto como unidade de análise nos PCN (BRASIL, 1998). Considerando que a noção teórica de letramento atravessa todos os "componentes curriculares" da BNCC (BRASIL, 2017), orientando as professoras a desenvolverem propostas de ensino que garantam a participação dos alunos em atividades interativas mediadas pela escrita em diversos domínios da sociedade, os gêneros textuais aparecem em meio às "competências", aos "objetos de conhecimento" e às "habilidades" elencadas. Nas orientações para o estudo da Geografia nos anos iniciais do Ensino Fundamental, é afirmado que "o estudo da Geografia [...], em articulação com os saberes de outros componentes curriculares e áreas de conhecimento, concorre para o processo de alfabetização e letramento". (BRASIL, 2017, p. 319).

Nas palavras de Silva (2009, p. 19) "os gêneros discursivos, tematizando assuntos específicos de interesse dos alunos, possibilitam a integração de atividades ou ações entre disciplinas". Em consonância com o pensamento do autor, o professor de Geografia ou de qualquer outro "componente curricular" pode negociar com os educandos possíveis 
encaminhamentos a partir do trabalho pedagógico mediado por gêneros textuais com os "objetos de conhecimento" selecionados.

Detendo-nos a algumas orientações oficiais para ensino de Geografia, passíveis de serem compartilhadas com outros "componentes curriculares", destacamos que, conforme a BNCC (BRASIL, 2017, p. 311), "o pensamento espacial [...] integra conhecimentos não somente da Geografia, mas também de outras áreas (como Matemática, Ciência, Arte e Literatura)". É o que ocorre, quando no estudo das regiões, são levantadas as manifestações artísticas e literárias de cada espaço geográfico do Brasil. Trata-se de uma oportunidade de diálogo entre as disciplinas fragmentadas pelo burocrático sistema educacional. Diferentes práticas sociais podem motivar transformações do currículo escolar.

As mudanças sempre provocam receio, portanto haverá barreiras a serem enfrentadas. Alunos e suas famílias podem questionar supostas fugas das temáticas disciplinares e os colegas geógrafos mais tradicionalistas tenderão a resistir a novas formas de ministrar aulas. Também os professores das demais disciplinas são facilmente tomados por sentimento de posse, e, movidos pela falsa ideia de que os conteúdos da disciplina de sua regência lhes pertencem, podem agir contra a interdisciplinaridade.

Em seu mundo restrito ao ambiente familiar, alguns alunos podem não ter uma ampla percepção dos fatos correntes no município, estado, país ou, até mesmo, no mundo. Então, as aulas de Geografia são muito úteis para o conhecimento espacial, com descrições das peculiaridades de cada localidade. É com a utilização de recursos facilitadores de compreensão e interação que as "competências" para os diferentes "componentes curriculares" podem ser alcançadas. E entre os variados materiais de uso pedagógico, computador, tablet e celular podem auxiliar na inovação das estratégias pedagógicas, atraindo a atenção dos estudantes.

Compreendemos que o trabalho pedagógico cooperativo passa a descontruir os saberes isolados, já que a interação revela uma maior capacidade de eficiência na resolução de problemas no trabalho, em casa, na escola ou em qualquer ambiente de circulação do indivíduo. Por isso, os projetos interdisciplinares estão em voga, nas unidades escolares contemporâneas, levando os profissionais da educação a saírem da posição de comodismo. Estes, motivados pela demanda social de um ensino em sintonia com a cidadania, fazem parte de uma realidade na qual os professores se encontram em formação continuada, na maioria das vezes, dispondo de seus próprios recursos financeiros para se adequarem a este fator preponderante para o sucesso docente, discente e da sociedade em geral.

A Geografia não pode carregar a representação de disciplina decorativa (com conteúdos a serem memorizados). Precisa ser reconhecida como um "componente curricular" caracterizado pela criticidade e resistência. Assim, as práticas sociais norteiam os debates com os estudantes e professoras de todas as áreas do conhecimento. Está formada a teia do saber por meio da qual os pensamentos e as ações ocorrem de maneira articulada e coerente. Desta forma, ao planejar aulas, o geógrafo se reúne com os colegas das áreas afins, como forma de promover o letramento geográfico além das fronteiras escolares.

Com formas mais democráticas de construção do conhecimento, os conteúdos de Geografia são assimilados mais facilmente e são demonstrados em projetos de cidadania, a exemplo de ações de intervenção em questões urgentes de recuperação do meio ambiente e conscientização das comunidades para a necessidade de mudança de comportamento. Para tanto, material gráfico deve ser produzido, o que requer parcerias para a construção de textos utilizando diferentes linguagens, até resultar na divulgação do conhecimento produzido na escola. Este propósito é efetivado apenas com a existência de um interesse em comum aliado à contribuição intelectual das várias áreas do conhecimento com objetivos compartilhados. Atividades como essas podem gerar produtivas possibilidades de letramento. 
Por fim, é importante considerarmos o domínio que os alunos possuem sobre as tecnologias digitais. Por um lado, muitos educadores consideram negativa a presença dos celulares em sala de aula, por exemplo, porque acreditam haver um significativo desvio de atenção e interesse dos alunos para conteúdos tidos como prejudiciais à aprendizagem, por isso os educadores proíbem o emprego dessas ferramentas argumentando ser a garantia de sucesso da aprendizagem. Por outro lado, há educadores que compartilham pontos favoráveis ao ensino mediado por tecnologias digitais. Neste sentido, o estudo de determinado "objeto de conhecimento" pode conduzir professoras e alunos a utilizarem ferramentas digitais que possibilitem a interação de saberes, o que estimula a aprendizagem e o desenvolvimento dos alunos.

Esta é uma ocasião propícia para a discussão sobre os impactos ambientais causados pelo descarte de materiais eletrônicos no meio ambiente, os quais são consumidos freneticamente. As causas e consequências do descarte insustentável precisam ser trabalhadas profundamente, incentivando os aprendizes a interferirem positivamente no quadro de destruição da natureza. Desta forma, o que poderia ser negativo na manipulação dos recursos tecnológicos, quando é redirecionado pedagogicamente, pode resultar em transformações sustentáveis da realidade (cf. HARGREAVES; FINK, 2007; SILVEIRA, 2016).

\section{Proposta de atividade pedagógica problematizada}

A proposta de análise linguística a partir do enfoque interdisciplinar entre os "componentes curriculares" focalizados neste artigo, Língua Portuguesa e Geografia, foi produzida a partir do gênero charge, cujo texto tematiza o desmatamento provocado principalmente por queimadas. Para elaborar a atividade analisada nesta seção, as professoras foram orientadas a trabalharem com algum "objeto de conhecimento" selecionado para o $9^{\circ}$ Ano, no "eixo" "conhecimentos linguísticos e gramaticais" da BNCC (BRASIL, 2017). As professoras escolheram trabalhar com conjunções, proposta na unidade Morfossintaxe, conforme reproduzimos no Exemplo 4.

Exemplo 4: "Objeto de conhecimento" selecionado

\begin{tabular}{|c|c|c|}
\hline \multicolumn{3}{|c|}{ LÍNGUA PORTUGUESA - 9º ANO (BRASIL, 2017, p. 146-147) } \\
\hline \multicolumn{3}{|c|}{$\begin{array}{l}\text { EIXO CONHECIMENTOS LINGUÍSTICOS E GRAMATICAIS - Práticas de análise linguística e } \\
\text { gramatical (como estratégia para o desenvolvimento produtivo das práticas de oralidade, leitura e escrita). } \\
\text { Reflexão sobre os usos do léxico e de regularidades no funcionamento da língua falada e escrita. }\end{array}$} \\
\hline $\begin{array}{l}\text { UNIDADES } \\
\text { TEMÁTICAS }\end{array}$ & $\begin{array}{c}\text { OBJETOS DE } \\
\text { CONHECIMENTO }\end{array}$ & HABILIDADES \\
\hline Morfossintaxe & $\begin{array}{l}\text { Observação de } \\
\text { regularidades no } \\
\text { funcionamento da } \\
\text { língua: conjunções } \\
\text { coordenativas e } \\
\text { subordinativas }\end{array}$ & $\begin{array}{l}\text { (EF09LP32) Identificar, em textos lidos e em } \\
\text { produções próprias, a relação que conjunções (e } \\
\text { locuções conjuntivas) coordenativas e subordinativas } \\
\text { estabelecem entre as orações que conectam. }\end{array}$ \\
\hline
\end{tabular}

Além de trabalhar com um "objeto de conhecimento" da Língua Portuguesa, as professoras também foram orientadas a selecionarem algum "objeto de conhecimento" da Geografia no mesmo ano, de maneira que a atividade pudesse proporcionar o trabalho cooperativo entre educadores responsáveis pelos mesmos alunos. $\mathrm{O}$ "impacto ambiental" foi escolhido como "objeto de conhecimento", conforme observável no Exemplo 5. Lembramos 
que as professoras não foram orientadas a aprofundar o trabalho pedagógico com $\mathrm{o}$ "componente curricular" parceiro, apenas a sinalizar alguma articulação que pudesse ser aproveitada pelo profissional responsável pela Geografia.

Exemplo 5: "Objeto de conhecimento" selecionado

\begin{tabular}{|c|c|c|}
\hline \multicolumn{3}{|c|}{ GEOGRAFIA - $9^{\circ}$ ANO (BRASIL, 2017, p. 344-345) } \\
\hline $\begin{array}{l}\text { UNIDADES } \\
\text { TEMÁTICAS }\end{array}$ & $\begin{array}{c}\text { OBJETOS DE } \\
\text { CONHECIMENTO }\end{array}$ & HABILIDADES \\
\hline \multirow[t]{2}{*}{$\begin{array}{l}\text { Natureza, ambientes e } \\
\text { qualidade de vida }\end{array}$} & \multirow[t]{2}{*}{$\begin{array}{l}\text { Impacto ambiental nos } \\
\text { Estados Unidos da } \\
\text { América, Brasil, África } \\
\text { e América espanhola }\end{array}$} & $\begin{array}{l}\text { (EF09GE16) Analisar características de países e } \\
\text { grupos de países da América e África no que se } \\
\text { refere aos aspectos populacionais, urbanos, políticos } \\
\text { e econômicos, e discutir as desigualdades sociais e } \\
\text { econômicas e as pressões sobre a natureza e suas } \\
\text { riquezas (sua apropriação e valoração na produção e } \\
\text { circulação), o que resulta na espoliação desses povos. }\end{array}$ \\
\hline & & $\begin{array}{c}\text { (EF09GE17) Analisar o papel ambiental e territorial } \\
\text { da Antártica no contexto geopolítico, sua relevância } \\
\text { para os países da América do Sul e seu valor como } \\
\text { área destinada à pesquisa e à compreensão do } \\
\text { ambiente global. }\end{array}$ \\
\hline
\end{tabular}

Conforme atividade reproduzida no Exemplo 6, a temática do "Impacto ambiental" será trabalhada na aula de Língua Portuguesa a partir da prática de leitura e de análise linguística do gênero charge, cujas linguagens verbal e não verbal conduzem à reflexão a respeito da ação humana sobre a natureza. No texto selecionado, um pai e um filho indígenas conversam diante de uma área desmatada consumida por incêndio. No diálogo, a criança, olhando para o desmatamento, afirma já ter crescido e compreendido a necessidade de receberem cestas básicas, o que, para muitos, pode significar uma prática assistencialista desnecessária. Essa situação representada no texto gera uma crítica à incoerência da exploração irresponsável da natureza pelo homem branco em função da aquisição de vantagens financeiras. 
Exemplo 6: Atividade proposta

\begin{tabular}{|c|}
\hline OBJETOS DE CONHECIMENTO: Impacto Ambiental e Leitura Mediada pela Análise \\
Linguística \\
\hline TEXTO 1: EXCERTO DE DIÁLOGO \\
\hline Pai?!! Agora que consegui crescer entendo precisamos de cesta básica para sobreviver. (Texto \\
adaptado) \\
\hline A partir do Texto 1, responda as quatro questões propostas abaixo:
\end{tabular}

1. Está faltando uma palavra no Texto 1. Identifique entre as alternativas abaixo a palavra ausente.
a) pois
b) porque
c) e
d) mas

2. Reescreva o Texto 1, acrescentando a palavra ausente.

Resposta: Pai?!! Agora que consegui crescer entendo porque precisamos de cesta básica para sobreviver.

3. A palavra ausente articula mais diretamente duas outras palavras do texto. Identifique essas duas palavras.

Resposta: A conjunção coordenativa explicativa articula a forma nominal no gerúndio "entendo" $e$ o verbo "precisamos". (Atenção professoras: os alunos não precisam utilizar as nomenclaturas gramaticais para responder a questão.)

4. Qual é a justificativa para que o filho compreendesse a necessidade da cesta básica para a sobrevivência?

Resposta: O crescimento do filho levou à compreensão.

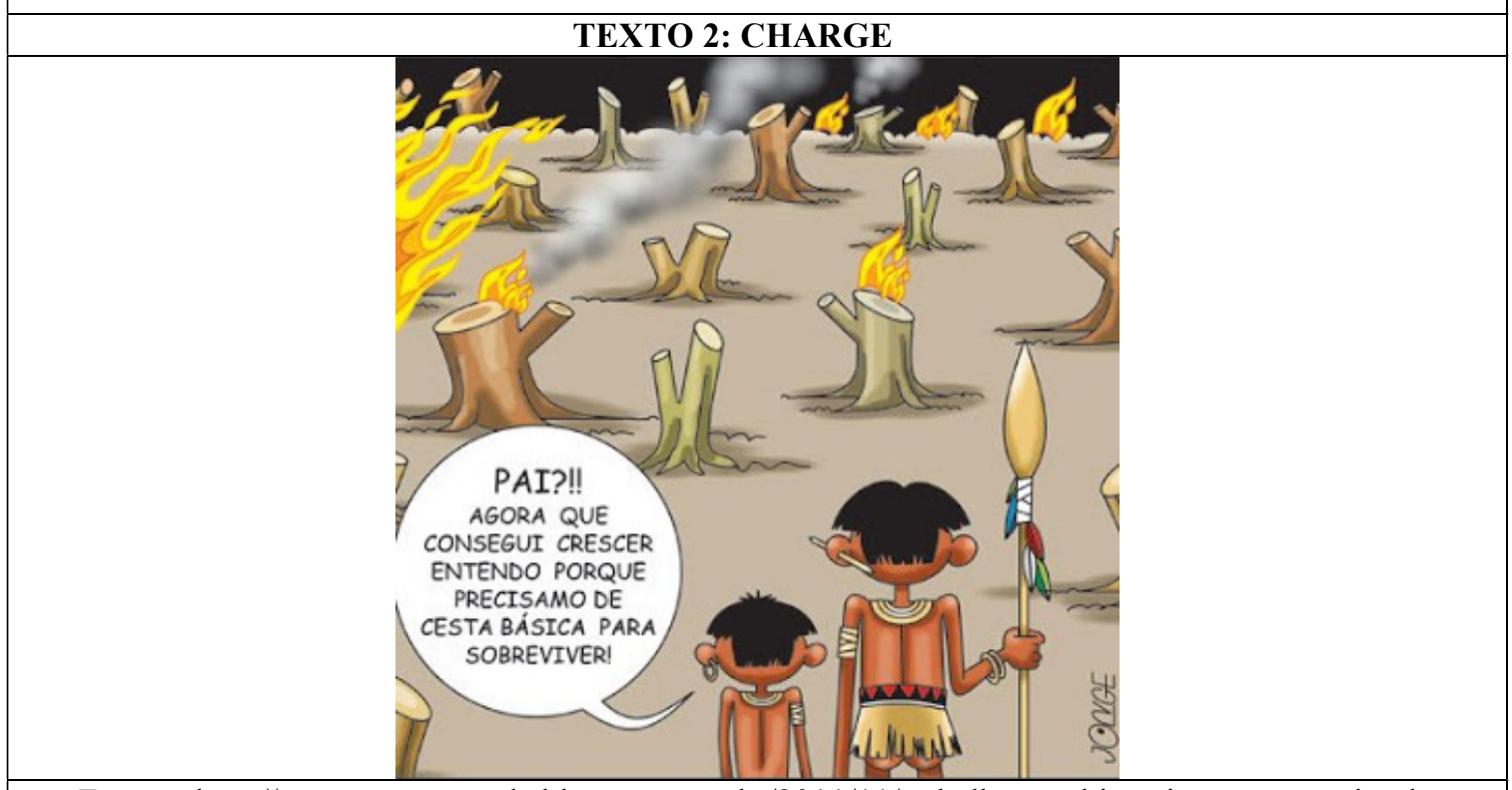

Fonte: <http://sucatasgreenverde.blogspot.com.br/2011/11/trabalhos-ambientais-comentem.html> Acesso: 18 jun. 2017.

A partir do Texto 2, responda as quatro questões propostas abaixo:

1. Apenas com a leitura da linguagem verbal do texto, você pode compreender a justificativa para a necessidade de receber cesta básica? Explique.

Resposta: Não. O leitor precisa considerar a queimada representada a partir do texto não verbal, da imagem.

2. A linguagem não verbal (imagem) acrescentou informações à leitura do texto verbal? Explique. 


\begin{abstract}
Resposta: Sim. Certamente, as árvores dão o sustento aos personagens nativos representados. Com a destruição da floresta, os nativos precisam do amparo do governo para sobreviver. O amparo oficial são as cestas básicas.
\end{abstract}

3. Tomando por base o conteúdo da charge, explique o significado da expressão "impactos ambientais". Se necessário realize uma pesquisa sobre o assunto ou, até mesmo, consulte o professor de Geografia.

Resposta: Os impactos ambientais diminuem a qualidade de vida, intensificado o problema da fome e o exodo rural.

4. Em dupla, produza uma charge que tematize outro tipo de impacto ambiental. Lembre-se da pesquisa realizada previamente.

Num primeiro momento, quando o excerto do diálogo é trabalhado, as professoras fizeram uma pequena adaptação do texto verbal da charge em função do enfoque da conjunção "porque". A sequência de questões revela um trabalho pedagógico na perspectiva da denominada "atividade epilinguística", na qual as questões enfatizam as construções gramaticais e seus efeitos de sentido dentro de textos pertencentes a gêneros específicos, evitando-se o uso de nomenclaturas e definições gramaticais (cf. FRANCHI, 2006).

O segundo momento da atividade, quando a charge é trabalhada diretamente, possibilita que os alunos percebam que um enunciado descontextualizado pode ganhar outro sentido. A linguagem não verbal ganha relevância na leitura do gênero charge. As duas últimas questões possibilitam um trabalho pedagógico articulado com a Geografia, levando os alunos a aprofundarem o conhecimento sobre os impactos ambientais a partir da pesquisa e, também, da produção textual de uma charge, gênero trabalhado previamente nas práticas de leitura e de análise linguística.

Em síntese, destacamos que, no âmbito do ProfLetras, a elaboração de atividades pedagógicas tem se configurado como um grande desafio paras as professoras em formação. $\mathrm{O}$ mestrado tem revelado que a elaboração de material didático, frequentemente, tem sido uma prática pouco conhecida pelas professoras. O desafio enfrentado pode ser desdobrado em dois aspectos responsáveis pelas dificuldades enfrentadas pelas professoras: (1) conhecimento linguístico do objeto a ser ensinado bastante restrito, a despeito dos anos de experiência que as professoras possuem trabalhando com os referidos conteúdos prontos em sala de aula; e (2) familiaridade limitada com o exercício da escrita, resultando na elaboração de enunciados confusos, os quais dificultam o alcance do propósito da atividade idealizada.

\title{
5 Considerações finais
}

A função social da escola está atrelada aos letramentos familiares dos alunos, construídos desde a mais tenra idade, relaciona-se ainda às demandas dos letramentos a serem apropriados pelos aprendizes. Em outras palavras, o manuseio pelos alunos de impressos diversos ou o escasso contato com a escrita, no contexto familiar, representam demandas distintas a serem respondidas pela escola.

O reconhecimento dessas demandas é necessário para a adequação das estratégias pedagógicas a serem assumidas pelos educadores. A prática de obediência das professoras às sequências de exercícios dos livros didáticos já não responde adequadamente aos anseios dos alunos contemporâneos. Assim, o suposto conforto da tradição do ensino cede espaço ao espírito investigativo das professoras, o que pode ser corroborado com o trabalho cooperativo entre educadores especialistas em diferentes "componentes curriculares".

Nessa perspectiva, podemos garantir a motivação dos estudantes durante o processo de ensino e aprendizagem, o fracasso escolar pode ser minimizado ou, até mesmo, eliminado. 
Retomando o texto utilizado como epígrafe deste artigo, precisamos de escolas que não alimentem os tropeços dos alunos "sobre complicações ortográficas". Precisamos de escolas que possibilitem a percepção dos alunos no tocante às riquezas constitutivas do trabalho com e sobre a língua portuguesa.

Por fim, lembramo-nos de que, em nosso cotidiano, os saberes não estão compartimentados. Compreendemos os fenômenos do cotidiano a partir de diferentes conhecimentos por nós compartilhados. $\mathrm{Na}$ escola e, inclusive, na universidade, as práticas não deveriam ser diferentes. Professoras, alunos e formadores/docentes precisam lidar com a complexidade constitutiva das coisas no mundo, abrindo mão da pseudofacilidade do trabalho com saberes compartimentados.

\section{Referências}

ANDRADE, C. D. Contos de aprendiz. 1 ed. São Paulo: Companhia das Letras, 2012.

BRASIL. Parâmetros Curriculares Nacionais: Ensino Fundamental II. Brasília: MEC, 1998. Base Nacional Comum Curricular. Brasília: MEC, 2017.

FRANCHI, C. Criatividade e gramática. In: POSSENTI, S. (Org.). Mas o que é mesmo "gramática"? São Paulo: Parábola Editorial, 2006, p. 34-101.

HARGREAVES, A.; FINK, D. Liderança sustentável: desenvolvendo gestores da aprendizagem. Porto Alegre: Artmed, 2007.

KLEIMAN, A. B. Texto e leitor: aspectos cognitivos da leitura. 5 ed. Campinas: Pontes Editores, 1997.

NEVES, M. H. M. Gramática na escola. São Paulo: Editora Contexto, 1999.

SILVA, W. R. Estudo da gramática no texto: demandas para o ensino e a formação do professor de língua materna. Maringá: EDUEM, 2011.

- Seleção textual no ensino interdisciplinar por projeto. Revista Brasileira de Linguística Aplicada. Belo Horizonte: UFMG, v. 9, n. 1, p. 17-39. 2009.

SILVEIRA, R. A. Abordagem interdisciplinar de práticas pedagógicas sustentáveis de letramentos numa escola tocantinense de tempo integral. Araguaína, 2016. 216f. Dissertação (Mestrado Profissional em Letras - ProfLetras) - Programa de Pós-Graduação em Letras. Universidade Federal do Tocantins.

SOARES, M. Alfabetização: a questão dos métodos. São Paulo: Contexto, 2017.

STREET, B. Letramentos sociais: abordagens críticas do letramento no desenvolvimento, na tecnologia, na etnografia e na educação. São Paulo: Parábola Editorial, 2014. Tradução Marcos Bagno.

Recebido em: junho de 2017.

Aprovado em: agosto de 2017. 